\title{
Methanogens, Methane and Gastrointestinal Motility
}

\author{
Konstantinos Triantafyllou, ${ }^{1,2}$ Christopher Chang ${ }^{1}$ and Mark Pimentel ${ }^{1 *}$ \\ ${ }^{1}$ GI Motility Program, Division of Gastroenterology, Cedars-Sinai Medical Center, Los Angeles, CA, USA; and ${ }^{2}$ Hepatogastroenterology Unit, \\ Second Department of Internal Medicine and Research Institute, Attikon University General Hospital, Medical School, Athens University, Athens, \\ Greece
}

Anaerobic fermentation of the undigested polysaccharide fraction of carbohydrates produces hydrogen in the intestine which is the substrate for methane production by intestinal methanogens. Hydrogen and methane are excreted in the flatus and in breath giving the opportunity to indirectly measure their production using breath testing. Although methane is detected in $30 \%-50 \%$ of the healthy adult population worldwide, its production has been epidemiologically and clinically associated with constipation related diseases, like constipation predominant irritable bowel syndrome and chronic constipation. While a causative relation is not proven yet, there is strong evidence from animal studies that methane delays intestinal transit, possibly acting as a neuromuscular transmitter. This evidence is further supported by the universal finding that methane production (measured by breath test) is associated with delayed transit time in clinical studies. There is also preliminary evidence that antibiotic reduction of methanogens (as evidenced by reduced methane production) predicts the clinical response in terms of symptomatic improvement in patients with constipation predominant irritable bowel syndrome. However, we have not identified yet the mechanism of action of methane on intestinal motility, and since methane production does not account for all constipation associated cases, there is need for high quality clinical trials to examine methane as a biomarker for the diagnosis or as a biomarker that predicts antibiotic treatment response in patients with constipation related disorders.

\section{(J Neurogastroenterol Motil 2014;20:31-40)}

Key Words

Constipation; Gastroparesis; Irritable bowel syndrome; Methane; Methanococcus

\section{Introduction}

The composition of gases generated in the intestine shows both inter-individual variability and variability among the differ- ent anatomical sites of the gastrointestinal tract. Hydrogen $\left(\mathrm{H}_{2}\right)$ and methane $\left(\mathrm{CH}_{4}\right)$ are mostly produced in the large intestine of normal subjects, during the partial or full fermentation of the undigested polysaccharide fraction of certain carbohydrates by the anaerobic flora. ${ }^{1}$ However, in cases of small bowel bacterial over-

Received: October 8, 2013 Revised: October 28, 2013 Accepted: October 29, 2013

(c) This is an Open Access article distributed under the terms of the Creative Commons Attribution Non-Commercial License (http://creativecommons. org/licenses/by-nc/3.0) which permits unrestricted non-commercial use, distribution, and reproduction in any medium, provided the original work is properly cited.

*Correspondence: Mark Pimentel, MD, FRCP(C)

GI Motility Program, Division of Gastroenterology, Cedars-Sinai Medical Center, 8730 Alden Drive, Suite 201E, Los Angeles, CA 90048, USA

Tel: +1-310-423-6143, Fax: +1-310-423-8356, E-mail: pimentelm@cshs.org

Financial support: None.

Conflicts of interest: None.

Author contributions: Konstantinos Triantafyllou designed, drafted and finally approved the manuscript. Christopher Chang designed, reviewed the manuscript for intellectual content and finally approved it. Mark Pimentel conceived the idea, reviewed the manuscript for intellectual content and finally approved it. 
growth (SIBO), these gases are produced in the small intestine and can be detected using breath testing - an indirect and easy method to detect SIBO. ${ }^{2}$

The quantitative equilibrium of gas concentrations in the intestine is delicate and one gas affects the other. $\mathrm{CH}_{4}$ is produced using $\mathrm{H}_{2}$ and $\mathrm{CO}_{2}$ during methanogenesis performed mainly by a group of anaerobes called methanogens in the intestine. Methanogenesis and methanogens are well known from livestock studies. Digestion of "roughage" in ruminant animals produces huge amounts of methane and measures have been undertaken to reduce cattle methane emissions either with diet modification or by introducing anti-menthanogen vaccination and antibiotics in order to control global warming and loss of energy. ${ }^{3}$

Methane has previously been considered an inactive gas that it is mainly excreted in flatus, while a certain amount is excreted in breath. ${ }^{4}$ However, recently, methane has been associated with gastrointestinal disorders, mainly chronic constipation and constipation predominant irritable bowel syndrome (IBS), ${ }^{4,5}$ as well as metabolic diseases like obesity. ${ }^{6}$

The purpose of this review is to provide comprehensive insights on methanogenesis and on the association of methane with gastrointestinal motility.

\section{Methanogens}

Among the numerous microorganisms that outnumber eukaryotic cells in human gut, methanogens are primitive "bugs" belonging to the Kingdom Archaea, one of the three distinct branches of the phylogenetic evolutionary descent; bacteria and eukaryota being the other two. These organisms are no longer considered prokaryotic organisms and share some similarities with the eukaryotic cells. ${ }^{7}$ They have some unique properties: live in strictly anaerobic conditions, ${ }^{8}$ difficult cultivation, requiring specific conditions and media, and cell wall lacking peptidoglycan making them therefore susceptible to certain antibiotics (i.e., chloramphenicol and bacitracin) and resistant to many common others like penicillins and aminoglycosides. ${ }^{10}$ The genetic diversity of methanogens in humans is limited ${ }^{11}$; only 3 phylotypes have been detected: Methaninobrevibacter smithii is the dominant methanogen in the intestine followed by Methanospaera stadmagnae ${ }^{12}$ whereas Methannobrevibacter oralis which is implicated in periodontal disease is the main archaeon in the oral cavity. ${ }^{13}$ Using molecular techniques, other archaea inhabitants of the human intestine have been identified, however, their role in health and disease and their co-operation with methanogens remains still
Table 1. Detection of Methanogens in Healthy Humans

\begin{tabular}{|c|c|c|}
\hline Method & Prevalence & Reference(s) \\
\hline $\begin{array}{l}\text { Quantitative PCR } \\
\text { (stool) }\end{array}$ & $\begin{array}{l}10 \% \text { of the anaerobes } \\
80.0-97.6 \%\end{array}$ & $\begin{array}{l}12 \\
17,18\end{array}$ \\
\hline $\begin{array}{l}\text { Quantitative PCR } \\
\text { (duodenal content) }\end{array}$ & $19.3 \%$ of the microbes & 25 \\
\hline $\begin{array}{l}\text { Breath test positivity } \\
\text { (baseline) }\end{array}$ & $54 \%$ & 36 \\
\hline $\begin{array}{l}\text { Breath test positivity } \\
(3 \mathrm{hr})\end{array}$ & $30 \%$ & 76 \\
\hline $\begin{array}{l}\text { Breath test positivity } \\
(>3 \mathrm{hr})\end{array}$ & $36-61 \%$ & $22,30,31$ \\
\hline Stool culture & $12 \%$ of the anaerobes & 15,16 \\
\hline
\end{tabular}

$\mathrm{PCR}$, polymerase chain reaction.

obscure. $^{14}$

Using either molecular ${ }^{12}$ or culture techniques, ${ }^{15,16}$ methanogens account for approximately $10 \%$ of the human colon anaerobes, whereas using modern polymerase chain reaction (PCR) techniques, $80 \%$ to almost $100 \%$ colonization of the human colon by $M$. smithii has been detected. ${ }^{17,18}$

There is evidence using quantitative PCR techniques that methanogens colonize in the human intestine early after birth. Methanogens were found in fecal samples of a 1 year old infant, ${ }^{19}$ while archaeal $16 \mathrm{~S}$ rRNA was detected even in the meconium. ${ }^{20}$ These finding support the hypothesis that contact with the mother's vaginal and intestinal flora during vaginal delivery might be an important source for the colonization of the infant gut. ${ }^{21}$ Moreover, studies in families ${ }^{22}$ and in twins ${ }^{23}$ support the hypothesis that environmental factors are associated with methanogenic flora transmission, independently of genetically predisposition. The distribution of methanogens in human colon is associated with the consistency of the feces; in the left colon where stool is solid, methanogens predominate. ${ }^{24}$ Recently, M. smithii was found in the human duodenum accounting for almost $20 \%$ of all microbes in this location. ${ }^{25}$ Table 1 presents the prevalence of methanogenic flora using different diagnostic tests.

\section{Methanogenesis and Methane}

Methanogenesis is a unique metabolic process whereby $\mathrm{CO}_{2}$ is reduced to $\mathrm{CH}_{4}$ using $\mathrm{H}_{2}$ produced by anaerobic bacterial fermentation as an electron donor. The procedure is undertaken by methanogens, although certain Clostiridium and Bacteroides species can also produce $\mathrm{CH}_{4}{ }^{26}$ Through this procedure metha- 
nogens obtain energy to survive and they reduce the gas molar volume in the intestine since for the production of 1 mole of $\mathrm{CH}_{4}$, $4 \mathrm{H}_{2}$ moles are consumed. ${ }^{27}$ However, methanogens compete with sulfate reducing bacteria and acetogenic bacteria for $\mathrm{H}_{2}$, and the outcome of the competition is governed by factors such as the availability of substrates, thermodynamics and $\mathrm{pH}$. As previously illustrated by Sahakian et $\mathrm{al}^{4}$, acetogenesis which is not common in the human colon (restricted to the right colon, if present) leads to acetate production through the least thermodynamically favorable process for the consumption of $\mathrm{H}_{2}$. Therefore, it is favored by the absence of methanogens and acidic $\mathrm{pH}$. In contrast, sulfide production is a more favorable thermodynamic process for $\mathrm{H}_{2}$ elimination but requires alkaline $\mathrm{pH}$ and a rare substrate (sulfate) in the human intestine. Due to low sulfate in human diet, an abundance of methanogenic flora and its substrate $\left(\mathrm{CO}_{2}\right)$, stool neutral $\mathrm{pH}$ and thermodynamics make $\mathrm{CH}_{4}$ production the dominant process for $\mathrm{H}_{2}$ consumption by intestinal microorganisms. ${ }^{4}$ However in certain occasions, such as ingestion of sulfate through alcoholic beverages (bear, wine and cider) or bread ${ }^{28}$ and hypochlorhydria that can change stool $\mathrm{pH}$ to alkaline may change the equilibrium in favor for sulphate-reducing bacteria.

Once produced, intestinal methane can be excreted either in the flatus or exhaled after traversing the gut mucosa and entering the systemic circulation without any further metabolism. ${ }^{22}$ Twenty $^{23}$ to fifty percent ${ }^{29}$ of the methane produced is excreted in the exhaled breath giving the opportunity for breath testing to become an indirect measurement of its production in the intestine.

Lactulose breath testing measures methane and hydrogen in breath samples obtained at baseline and every 15 to 20 minutes after 10 grams lactulose ingestion until 180 minutes or even later, using gas chromatography. Methane breath testing shows 2 discrete patterns of the gas production after lactulose ingestion: (1) high baseline level and early rise in the breath methane, associated probably with SIBO production; and (2) late rise, corresponding to the arrival of lactulose at the left colon, where methanogens di- gest it in normal humans. ${ }^{30}$

While lactulose is usually the substrate for breath testing, other substrates like glucose and sucrose have also been used. Methane breath testing positivity is variably defined in the literature depending on the substrate and the cut-off used: it ranges from $>1$ part per million (ppm) above the atmospheric concentration $(1.8 \mathrm{ppm})^{22,31}$ to $\geq 3 \mathrm{ppm}^{32,33}$ and $>10 \mathrm{ppm}^{34}$ any time during the test.

Based on early study, ${ }^{22}$ individuals are categorized as methane producers and non-producers, accounting approximately for the $35 \%$ and $65 \%$ of a healthy Western population, respectively. Surprisingly, the proportion of methane producers remained stable over 35 years between 1970 and 2005, despite increase in antibiotics consumption and diet modifications that occurred during the same period. ${ }^{31}$

An absence of methane in the breath does not mean absence of methanogenic flora. On the contrary, methanogens are present in the vast majority of the health adults' flora, almost universally. ${ }^{6}$ However, it seems that there is a threshold of approximately $10^{8}$ methanogens per gram dry weight of stool in order to detect the generated methane in breath sample ${ }^{35}$; and methane producers harbor $10^{7}$ to $10^{10}$ methanogens per gram dry weight of stool. ${ }^{27}$

In contrast to Bond et $\mathrm{al}^{22}$ recent studies indicate that the prevalence of healthy adults methane producers ranges between $36 \%$ and $63 \% .^{30,31,36}$ Several factors have been associated with this wide range. One of them is the definition of methane positivity. While recently, methane positivity is defined based on early (180 minutes) breath test positivity, other studies estimate methanogens prevalence using late breath testing positivity or baseline positivity (Table 1).

Table 2 presents the predisposing factors for methane breath testing positivity in healthy humans. Geographic differences appear important with the highest prevalence in Nigeria and in South Africa (77\% and $87 \%$, respectively) ${ }^{37,38}$ and the lowest in Norway and in Minneapolis-area (34\% and 35\%, respective-

Table 2. Predisposing Factors for Methane Breath Test Positivity in Healthy Humans

\begin{tabular}{ll}
\hline Predisposing factor & \multicolumn{1}{c}{ Methane detection in breath test } \\
\hline Geographical area & Higher in Africa \\
& Lower in USA-Europe \\
Socioeconomic status & High in lower socioeconomic situations \\
Gender & Higher in females than in males \\
Age & Age $<3$ yr: undetectable \\
& Age 3-15 yr: increases and reached adults levels by adolescence \\
Family clustering & Similar levels between sibling, parents and children but not in spouses \\
\hline
\end{tabular}


ly). ${ }^{31,39}$ Female sex has been also associated with $\mathrm{CH}_{4}$ positive producer status in many studies, ${ }^{22,39-41}$ but not universally. ${ }^{31}$ Age is linked to breath methane detection; while methane is not detected in breath of children aged $<3$ years, ${ }^{20,31,37}$ its detection reaches the prevalence of adults by adolescence. ${ }^{22,36}$

It has been shown that there is a family clustering of $\mathrm{CH}_{4}$ production, being similar between siblings and in parents and children but not in spouses ${ }^{22}$ indicating that environmental factors are also important for methane production, similar to the findings of the molecular studies discussed previously. ${ }^{23}$ More precisely, low (9\%) but existence of discordance between identical twins, ${ }^{22}$ and not so high concordance rate between monozygotic twins, which was similar in dizygotic twins ${ }^{23}$ indicate a role for environmental factors. However, one twin study challenged this hypothesis, indicating the presence of genetically predisposition as well. ${ }^{42}$

Recently, methane production status has been related with low socioeconomically conditions. High methane production was detected in children living in slum area irrespective of the presence of SIBO, suggesting that methane measurement might be an indicator of environment contamination. ${ }^{43}$

\section{Methane and Disease Associations}

Certain gastrointestinal diseases have been associated with positive methane producer status, including colon cancer. As early as in 1977, Heins and his colleagues ${ }^{44}$ showed that the number of methane producers among patients with colorectal cancer occluding the left colon was double than that of the general population, indicating a possible relation between methane production and colon cancer. However, following this observation there were only two more small studies in favor of this association while 10 studies failed to confirm it, as illustrated by Roccarina et al. $^{5}$ Diverticulosis is associated with methane production ${ }^{35,45}$ and while diarrheal conditions like inflammatory bowel disease are negatively associated with methane production, ${ }^{29,33}$ there is strong evidence that methane is positively associated with intestinal motility disorders like constipation ${ }^{32,46}$ and constipation predominant IBS. ${ }^{4,33,47}$

\section{Physiological Effects of Methane}

Recent data ${ }^{48}$ has challenged the perception that methane and slowed intestinal motility just coexist or that the abundance of methane is secondary to impaired intestinal motility and proposed that there is a causative relation of methane production and intes- tine motility disturbance. Investigators showed in a three-part translational and human study that: (1) intestinal methane infusion through surgically created fistulae in an in vivo canine model significantly slowed small intestinal transit time by $59 \%$, as assessed by scintigraphy; (2) exposure to methane augmented ileal circular muscle contractile activity in an ex vivo guinea pig ileum experiment; and (3) IBS methane producers had significantly higher fasting and post-prandial motility indices, as well as, isolated fasting contractions during antro-duodenal manometry compared to IBS $\mathrm{H}_{2}$ producers. The consistency of the motility findings in response to methane in the animal models and in human subjects provided for the first time experimental evidence that methane may not be an inert intestinal gas, but it can intervene to the neuromuscular function of the intestinal track. Moreover, the results in the isolated ileum segment of the guinea pig experiment support a topical than a brain-gut axis methane action.

The evidence for rather causative association of methane with delayed intestinal motility was further augmented by an elegant experiment that aimed to further explore possible effects of gases produced in the intestine in the ileum and colon motility. Investigators showed in an ex vivo experiment using guinea pig ileal, right and left colon segments in a peristaltic tissue bath that: (1) ileal contractile activity significantly decreased and the amplitude of peristaltic contractions increased when methane was pumped in the bath, while the opposite phenomenon was detected after $\mathrm{H}_{2}$ infusion; (2) colonic transit was shortened by hydrogen infusion, but this effect was diminished when methane was additionally pumped; these effects being more prominent in the right colon. ${ }^{49}$

Although there are limitations in animal and gas perfusion studies to mimic the physiological status of the intestinal environment, these two translational studies provide experimental evidence to support a direct action of methane to delay intestinal transit time.

Intestinal transit time is a physiological marker of intestinal motility. It can be measured by different ways, e.g., stool frequency, whole gut, orocecal and colonic transit time etc., with the implementation of simple or very sophisticated investigations. ${ }^{50}$ Due to these differences, it is very difficult to combine the results of these studies. Table 3 summarizes seven adult ${ }^{30,31,51-55}$ studies that included 171 and 287 methane producers and non-producers, respectively. There is a clear association of methane production and slow intestinal transit, irrespective of health status (healthy, IBS or constipated individuals) and of the method used 
Table 3. Methane Production and Gastrointestinal Transit (Modified from Kunkel et al ${ }^{46}$ )

\begin{tabular}{|c|c|c|c|c|c|c|}
\hline Study & Condition studied & Measurement of transit & $\mathrm{MP} / \mathrm{MnP}(\mathrm{n})$ & MP transit & $\mathrm{MnP}$ transit & $P$ \\
\hline Cloarec et al ${ }^{30}(1990)$ & Healthy adults & Orocecal transit time $(\mathrm{min})$ & $40 / 25$ & $111 \pm 52$ & $68 \pm 24$ & $P<0.005$ \\
\hline Levitt et $\mathrm{al}^{31}(2006)$ & Healthy adults & Stool frequency (bm/day) & $78 / 134$ & $1.03 \pm 0.08$ & $1.11 \pm 0.06$ & NS \\
\hline Chatterjee et $\mathrm{al}^{51}(2007)$ & IBS adults & Stool frequency (bm/day) & $20 / 67$ & $1.17 \pm 0.86$ & $1.96 \pm 1.40$ & $P<0.05$ \\
\hline Rumessen et al ${ }^{52}$ (1994) & Healthy adults & Orocecal transit time (min) & $7 / 7$ & 75 & 60 & NS \\
\hline Stephen et al ${ }^{53}(1986)$ & Healthy adults & Whole gut transit time (hr) & $9 / 21$ & $84.6 \pm 11.7$ & $48.6 \pm 6.6$ & $P<0.05$ \\
\hline Oufir et al ${ }^{54}$ (1996) & Healthy adults & Whole gut transit time (hr) & $4 / 4$ & 95.5 & 50 & $P<0.05$ \\
\hline Morken et al ${ }^{55}$ (2007) & IBS-like adults & Whole gut transit time (hr) & $13 / 29$ & $141 \pm 14$ & $95 \pm 8$ & $P<0.005$ \\
\hline
\end{tabular}

$\mathrm{MP}$, methane producers; $\mathrm{MnP}$, methane non-producers; bm, bowel movements.

to assess transit in all of them. Even in the two studies ${ }^{31,52}$ in which statistical significance was not reached, a numerical difference was detected.

There are two more studies that due to different estimation of intestinal motility-using the motility index ${ }^{48,56}$-are not included in the Table 3. Both studies showed that methane breath test positivity was related to higher fasting motility index, while the study of Pimentel et $\mathrm{al}^{48}$ showed a higher postprandial motility index in methane producing subjects, as well. Finally, there are 2 studies $^{57,58}$ revealing that the prevalence of methane producers was higher in the slow transit ( $75 \%$ and $58.8 \%$ ) compared to the normal transit (44\% and $12.2 \%$ ) chronic constipated patients and to the healthy controls (28\% and $13.3 \%)$, respectively. Therefore, data universally support that production of methane as determined by breath testing, is associated with delayed intestinal transit. However, the mechanisms of transit delay induced by methane are still unclear. A small study that evaluated 18 Rome I IBS patients (4 methane producers) showed that the postprandial serotonin level in methane producing patients was lower than in hydrogen producers, implicating methane to serotonin production for the regulation of intestinal motility. ${ }^{59}$

\section{Irritable Bowel Syndrome}

IBS is the most common functional disorder characterized by the presence of abdominal pain and altered bowel habits. Based on the predominant symptom, IBS is broadly divided to constipation predominant (C-IBS) and diarrhea predominant (D-IBS) syndrome, and evidence is accumulating for a strong association between intestinal methane production and C-IBS. ${ }^{4,5}$

Overall, the prevalence of methane producers among IBS sufferers varies. It ranges from low (14.5\% to $15 \%)^{60,61}$ to higher (23.8\% to $34.4 \%) .{ }^{62,63}$ Reasons to explain these differences may include among others, varied definitions of IBS status, different mix of the 2 main subtypes of the syndrome, controls "contami- nation" with quiescent IBS or IBS-like symptoms as well as variability in the detection of methane and in the definition of the methane producer and ethnic differences. Table 4 summarizes studies supporting an association of methane and constipation related disorders: C-IBS and chronic constipation. As early as in 2003, it was shown that a breath test with detectable methane could discriminate constipation and diarrheal diseases: a positive methane lactulose breath test showed $100 \%$ association with C-IBS patients while the gas was almost nonexistent in the predominantly diarrheal conditions of inflammatory bowel diseases. ${ }^{32}$ Moreover, subjectively assessed constipation and diarrhea severity scores were higher in methane and hydrogen producers, respectively. ${ }^{32}$ The relationship between constipation and methane production was also proved in a more detailed nested study that assessed constipation severity using both subjective (patients perception) and objective (number of bowel movements and Bristol stool score) measures in 87 Rome I IBS patients. ${ }^{51}$ In this study, constipation severity was significantly related to methane producer status and to the quantity of methane production during the lactulose breath testing, whereas methane production was correlated to a lower number of bowel movements and Bristol stool score. Furthermore, a study that assessed among many other parameters, stool frequency and consistency, showed that Rome II IBS methane predominant producers on sucrose breath testing reported more often less than three defecation per week and hard or lumpy stools compared to hydrogen producers. ${ }^{56}$ In a study evaluating SIBO in 204 Rome II IBS patients, there were more methane producers in C-IBS than in D-IBS group (58\% vs. $28 \%$ ) while D-IBS had more hydrogen producers (71\% vs. $42 \%$ ) during the glucose breath testing. ${ }^{63}$ Finally, among Rome II IBS subjects with bloating and flatulence as predominant symptoms, logistic regression analysis revealed that methane was the main intestinal gas detected in C-IBS patients (OR, 8; 95\% CI, 1.3-44.0), using glucose breath testing. ${ }^{64}$ The results of these 
Table 4. Studies Supporting the Asociation Between Methane Production and Constipation Related Disorders in Adults

\begin{tabular}{|c|c|c|c|c|}
\hline Study & $\begin{array}{l}\text { Condition } \\
\text { studied }\end{array}$ & Breath test & $\begin{array}{l}\text { Total/methane } \\
\text { producers }(\mathrm{n})\end{array}$ & Criterion for the association \\
\hline Peled et $\mathrm{al}^{62}(1987)$ & IBS & & $32 / 11$ & Association with symptoms \\
\hline Pimentel et $\mathrm{al}^{32}$ (2003) & IBS & Lactulose & $296 / 50$ & Severity of constipation; $100 \%$ association with C-IBS \\
\hline Pimentel et $\mathrm{al}^{68}$ (2003) & IBS & Lactulose & $65 / 12$ & Severity of constipation; $100 \%$ association with C-IBS \\
\hline Pimentel et $\mathrm{al}^{73}$ (2006) & C-IBS & Lactulose & $39 / 12$ & Therapeutic criterion \\
\hline Chatterjee et al ${ }^{51}(2007)$ & IBS & Lactulose & $87 / 20$ & Severity of constipation; stool frequency and consistency \\
\hline Majewski and McCallum ${ }^{63}$ (2007) & IBS & Glucose & $204 / 32$ & Clinical association with C-IBS \\
\hline Bratten et $\mathrm{al}^{61}(2008)$ & IBS & Lactulose & $224 / 44$ & Association with constipation \\
\hline Grover et $\mathrm{al}^{56}(2008)$ & IBS & Sucrose & $158 / 10$ & $\begin{array}{l}\text { Association with C-IBS; correlation with the motility index; } \\
\text { relation to stool consistency }\end{array}$ \\
\hline Hwang et $\mathrm{al}^{33}$ (2010) & IBS & Lactulose & $56 / 28$ & Methane predicts C-IBS with high sensitivity and specificity \\
\hline Attaluri et $\mathrm{al}^{57}(2010)$ & $\mathrm{CC}$ & Glucose & $202 / 87$ & Correlation with transit time \\
\hline Reddymasu et al ${ }^{64}(2010)$ & IBS & Glucose & 98/NM & Association with C-IBS \\
\hline Low et $\mathrm{al}^{74}(2010)$ & IBS & Lactulose & $74 / 74$ & Therapeutic criterion \\
\hline 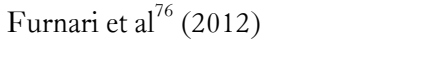 & IBS and CC & Glucose & $629 / 203$ & $\begin{array}{l}\text { Relation to constipation overall; higher methane excretion (ppm) } \\
\text { in CC compared to C-IBS patients }\end{array}$ \\
\hline Lee et $\mathrm{al}^{58}$ (2013) & Constipation & Lactulose & $62 / 16$ & Correlation with transit time \\
\hline
\end{tabular}

IBS, irritable bowel syndrome; C-IBS, constipation IBS; CC, chronic constipation; NM, not mentioned in the paper; ppm, parts per million.

studies were recently challenged by a study that failed to detect any association between IBS symptoms and methane positivity on lactulose breath testing in 68 IBS patients fulfilling the Rome III criteria (34\% C-IBS). ${ }^{65}$ Mean symptom severity scores using a visual analogue scale for constipation and diarrhea were not related to methane producer status. However, investigators revealed a weak association between methane positivity and bloating, flatulence and abdominal pain. To the best of our knowledge so far, this is the only study that has not revealed an association between methane breath test positivity and constipation in IBS. However, the authors acknowledge that the study design incorporated a broad subjective definition of constipation without measuring stool frequency and consistency which might be responsible for the discrepant results. ${ }^{65}$

Since there is no a specific examination, not even a surrogate marker, for the diagnosis of IBS, this diagnosis of the syndrome is symptom based, as proposed by the Rome Foundation. ${ }^{66}$ However, methane detected in a breath testing is a candidate biomarker for constipation associated disorders. Indeed, a prospective, double blind, head to head comparison of methane positivity in lactulose breath test and Rome I IBS classification showed that methane positivity had a sensitivity of $91.7 \%$ and a specificity of $81.3 \%$ to correctly assign subjects to the C-IBS group. ${ }^{33}$ Furthermore, a meta-analysis of nine studies that examined 1,277 individuals found a significant association between methane positivity in breath testing and constipation associated disorders (OR, 3.51; 95\% CI, 2.0-6.16). More importantly, the association remained significant (OR, 3.60; 95\% CI, 1.84-6.54) when only IBS studies were examined. ${ }^{46}$ These 2 aforementioned studies indicate that methane could potentially become a biomarker for constipation associated bowel diseases. However before adopting a diagnostic strategy like that, we must have in mind that methane is present in a certain proportion in healthy individuals, methane does not account for all constipation, there are constipated and C-IBS patients without production of methane in the breath test and therefore, methane cannot be considered the exclusive cause of the symptoms. ${ }^{46}$

Beyond constipation or diarrhea, IBS is a "constellation" of symptoms rather than a single predominant symptom. ${ }^{67} \mathrm{~A}$ sophisticated factor analysis was conducted in order to explore the relationship between various gastrointestinal symptoms and the presence of methane in Rome I IBS subjects. Patients answered a 31 item questionnaire on the severity of their gastrointestinal symptoms and underwent a lactulose breath test. The study showed that IBS methane producers have a different set of symptoms (constipation, small bowel movements, straining, lack of milk intolerance and lack of weight loss) as compared to non-producers (diarrhea, pain during and after defecation, large and foul smelling stool, urgency and weakness after the defecation) proposing again a biomarker role for IBS in order to provide patients 
treatment beyond laxatives for constipation. ${ }^{67}$

A further step toward the clarification of methane's role in IBS was made by identifying the incidence and type of methanogens in C-IBS patients. In a study that included nine Rome II C-IBS methane producers and 10 IBS non-methane subjects, quantitative PCR revealed that $M$. smithii was the predominant methanogen in all IBS patients. However, absolute counts and relative to other stool bacteria proportion of the archaeon were significantly higher in methane positive patients. Furthermore, the quantity of $M$. smithii was proportional to the amount of methane excreted in breath, raising the question of whether $M$. smithii PCR stool testing would be more sensitive than breath methane for the diagnosis of C-IBS and for the identification of a subgroup of C-IBS who would benefit from antibiotic treatment. ${ }^{47}$

Antibiotic treatment of IBS with poorly absorbable antibiotics has gained scientific attention during the last decade. After the original trial with neomycin, ${ }^{68}$ three fully-published and one in abstract form, double blind, placebo controlled trials of rifaximin ${ }^{69-72}$ suggest an improvement in IBS symptoms related to SIBO eradication.

In a sub-analysis of the neomycin trial, ${ }^{73}$ there were 12 methane positive patients among the 111 original study participants and all of them belonged to C-IBS group. Neomycin treatment in methane producers $(n=5)$ resulted in significant improvement of constipation compared to placebo, concluding that the antibiotic use benefit in C-IBS patients is dependent on methane on breath testing.

In further work, the same group performed a retrospective analysis of treatment data among C-IBS patients. ${ }^{74}$ In all methane positive patients, the treatment of choice was neomycin, rifaximin and the combination of the 2 medications before 2004, between 2004 to 2007 and after 2007, respectively. Data showed that the combination of the 2 drugs was most effective in inducing clinical improvement and in eliminating methane for methane producers ( $85 \%$ and $87 \%$, respectively).

These 2 treatment studies, although they have certain limitation regarding design, clinical outcome definition and small number of included patients, provide further evidence for the use of breath test methane positivity as a biomarker to identify C-IBS patients that may benefit from antibiotic treatment. Moreover, this biomarker can provide objective monitoring of the treatment effect, since the clinical response correlates with methane elimination. $^{73,74}$

\section{Chronic Constipation}

Chronic constipation is another bowel functional disorder which is broadly divided into normal and slow transit constipation and in evacuation disorders. ${ }^{66}$ According to Rome III, functional constipation and C-IBS are different entities, however the results of a recent provocative study indicate that they are not distinct disorders, but rather lie in the spectrum of visceral sensitivity which is modulated by serotonin. ${ }^{75}$

The relation of methane production and functional constipation has also been examined, albeit less than in IBS. In a study of 96 Rome III chronic constipation patients and 106 controls, symptoms were evaluated using questionnaire, methane positivity was examined using glucose breath testing and colon transit time was measured using radiopaque markers. Methane positivity was detected in $75 \%, 44 \%$ and $28 \%$ of the slow transit (ST) patients, normal transit (NT) patients and controls, respectively. Methane production was highest in the ST followed by the NT patients and it correlated with colon transit time. ${ }^{57}$ Surprisingly, methane production was not related to stool frequency or consistency in contrast to findings in C-IBS. ${ }^{51}$

In another retrospective study, 62 Rome III constipated patients and 49 controls had lactulose breath testing for methane production and an accurate colon transit time measurement with markers. Investigators showed that breath methane was positive in $58.8 \%, 13.3 \%$ and $12.2 \%$ in the ST, NT patients and controls, respectively. ${ }^{58}$ Colon transit, and more prominently left colon transit time, appeared related to the total production of $\mathrm{CH}_{4}$. However, methane positivity was not related with stool consistency. Furthermore, investigators did not reveal any relationship between methane production and anorectal manometry findings. ${ }^{58}$

Using a different approach, the association of $\mathrm{CH}_{4}$ production and various functional gastrointestinal symptoms was studied prospectively in a set of 629 patients and 40 controls, using questionnaire symptom assessment and glucose breath test. ${ }^{76}$ Methane positivity was similar among patients and controls (32.3\% and $30 \%$, respectively), however there was significantly more methane production in patients $(21.1 \mathrm{ppm}$ vs. $6.1 \mathrm{ppm} ; P$ $=0.045$, respectively) than in control. Regression analysis revealed that methane excretion was related only to constipation. When constipated patients were divided in those with chronic constipation and C-IBS, methane production was higher in the chronic constipation patients (30.3 ppm vs. $21.5 \mathrm{ppm} ; P=$ 0.046 , respectively) than in C-IBS patients. ${ }^{76}$

In contrast to $\mathrm{C}$-IBS methane eradication treatment data, 
there is absence of trials evaluating the effects of antibiotic treatment in methane production and symptom resolution in functional constipation. There is only one case report ${ }^{77}$ of a patient with slow transit constipation and methane positivity (while fasting and after glucose ingestion) whose stool frequency and consistency improved, and colon transit accelerated after 14 days treatment with refaximin $400 \mathrm{mg}$ t.i.d. Moreover, glucose breath methane excretion 10 days after end of treatment was $<5$ ppm compared to $36 \mathrm{ppm}$ before treatment, indicating that constipation improvement was related to methane eradication.

\section{Gastroparesis}

Gastroparesis symptoms include postprandial fullness, early satiety, abdominal pain, nausea, vomiting and bloating without obstruction. It may be idiopathic or secondary to diabetes mellitus, gastric-surgical procedures and opioid consumption etc. ${ }^{78}$ Interestingly, while gastric emptying is delayed, gastroparesis symptoms do not correlate well with the degree of the delay assessed by scintigraphy, suggesting that other factors may contribute to the development of symptoms. ${ }^{79}$

Although the evidence is still poor to reach firm conclusions, we report herein the only two available studies that have evaluated methane production in gastroparesis patients. SIBO has been detected by positive glucose methane breath testing in $27 \%$ of 50 gastroparesis patients complaining mainly about abdominal pain and bloating. ${ }^{80}$ In a larger study evaluating 201 patients with symptom severity questionnaire, scintigraphic gastric emptying measurement and lactulose breath testing, only $6(3 \%)$ patients had positive methane breath test (breath methane increase of $>$ 20 ppm above baseline by 90 minutes) and there was no relation of methane positivity to gastric emptying time and severity of symptoms. $^{81}$

\section{Conclusions}

Methane is a unique gas produced in strict anaerobic conditions by intestinal methanogens that metabolize $\mathrm{H}_{2}$, one of the end products of bacterial fermentation. Although thought of as an inert gas, there is evidence from translational medicine that methane acts like a neuromuscular transmitter resulting in reduced propagation of the peristaltic movement in the intestine. This evidence is further supported by the universal finding in physiological studies that $\mathrm{CH}_{4}$ production (measured by breath testing) delays transit time and by clinical studies showing a relationship between methane status on breath testing with delayed transit associated conditions like constipation predominant IBS and chronic constipation. There is also preliminary evidence that antibiotic treatment results in improvement of symptoms in a certain proportion of patients suffering from these disorders in a fashion related to its ability to eradicate methane. However, methane is also detected in healthy individuals and all constipation patients and symptoms are not associated with high methane production, meaning that there is plenty of room for research to identify the mechanism of action of methane on intestinal motility before recommending methane as a biomarker for the diagnosis of constipation related disorders or as a biomarker for selecting patients who may benefit from antibiotic eradication of methane.

\section{References}

1. Chassard C, Lacroix C. Carbohydrates and the human gut microbiota. Curr Opin Clin Nutr Metab Care 2013;16:453-460.

2. de Lacy Costello BPJ, Ledochowski M, Ratcliffe NM. The importance of breath testing: a review. J Breath Res 2013;7:024001.

3. Eckard RJ, Grainger C, de Klein CAM. Options for abatement of methane and nitrous oxide from ruminant production: A review. Livest Sci 2010;130:47-56.

4. Sahakian AB, Jee SR, Pimentel M. Methane and the gastrointestinal tract. Dig Dis Sci 2010;5 5:2134-2143.

5. Roccarina D, Lauritano EC, Gabrielli M, Franceschi F, Ojetti V, Gasbarrini A. The role of methane in intestinal diseases. Am J Gastroenterol 2010;1250-1256.

6. Mathur R, Amichai M, Chua KS, Mirocha J, Barlow GM, Pimentel $\mathrm{M}$. Methane and hydrogen positivity on breath test is associated with greater body mass index and body fat. J Clin Endocrinol Metab 2013;98:E698-E702.

7. Jones WJ, Nagle DP Jr, Whitman WB. Methanogens and the diversity of the archaebcteria. Microbiol Rev 1987;51:135-177.

8. Forterre P, Brochier C, Philippe H. Evolution of the archaea. Theor Popul Biol 2002;61:409-422.

9. Khelaifia S, Raoult D, Drancourt M. A versatile medium for cultivating methanogenic archaea. PLoS One 2013;8:e61563.

10. Khelaifia S, Drancourt M. Susceptibility of archaea to antimicrobial agents: applications to clinical microbiology. Clin Microbiol Infect 2012;18:841-848.

11. Scanlan PD, Shanahan F, Marchesi J. Human methanogen diversity and incidence in healthy and diseased colonic groups using $\mathrm{mrcA}$ gene analysis. BMC Microbiol 2008;8:79.

12. Eckburg PB, BiK EM, Bernstein CN, et al. Diversity of the human intestinal microbial flora. Science 2005;308:1635-1638.

13. Lepp PW, Bring MM, Ouverney CC, Palm K, Armitage GC, Relman DA. Methanogenic archaea and human periodontal disease. Proc Natl Acad Sci USA 2004;101:6176-6181.

14. Nam YD, Chang HW, Kim KH, et al. Bacterial, archaeal and eukaryal diversity in intestines of Korean people. J Microbiol 2008; 46:491-501. 
15. Miller TL, Wolin MJ. Enumeration of Methanobrevibacter smithii in human feces. Arch Microbiol 1982;131:14-18.

16. Pochart P, Lémann F, Flourié B, Pellier P, Goderel I, Rambaud JC. Pyxigraphic sampling to enumerate methanogens and anaerobes in the right colon of healthy humans. Gastroenterology 1993;105:1281-1285.

17. Matarazzo F, Ribeiro AC, Faveri M, Taddei C, Martinez MB, Mayer MP. The domain Archaea in human mucosal surfaces. Clin Microbiol Infect 2012;18:834-840.

18. Dridi B, Henry M, El Khéchine A, Raoult D, Drancourt M. High prevelance of Methanobrevibacter smithii and Methanosphaera stadtmanae detected in the human gut using an improved DNA detection protocol. PLoS ONE 2009;4:e7063.

19. Palmer C, Bik EM, Di Giulio DB, Relman DA, Brown PO. Development of the human infant intestinal microbiota. PLoS Biol 2007;5:e177.

20. Koenig JE, Spor A, Scalfone N, et al. Succession of microbial consortia in the developing infant gut microbiome. Proc Natl Acad Sci USA 2011;108(suppl 1):4578-4585.

21. Neu J, Rushing J. Cesarean versus vaginal delivery: long term infant outcomes and the hygiene hypothesis. Clin Perinatol 2011;38:321-331.

22. Bond JH Jr, Engel RR, Levitt MD. Factors influencing pulmonary methane excretion in man. J Exp Med 1971;133:572-588.

23. Florin TH, Zhu G, Kirk KM, Martin NG. Shared and unique environmental factors determine the ecology of methanogens in humans and rats. Am J Gastroenterol 2000;95:2872-2879.

24. Flourié B, Etanchaud F, Florent C, Pellier P, Bouhnik Y, Rambaud JC. Comparative study of hydrogen and methane production in the human colon using caecal and faecal homogenates. Gut 1990;31:684-685.

25. Kim G, Giamarellos-Bourboulis EJ, Pyleris E, et al. Methanobrevibacter Smithii is found in human duodenum and is associated with altered luminal cytokines. Gastroenterology 2012;142:S-98.

26. McKay LF, Holbrook WP, Eastwood MA. Methane and hydrogen production by human intestinal anaerobic bacteria. Acta Microbopl Immunol Scand B 1982;90:257-260.

27. Blaut M. Metabolism of methanogens. Antoine Van Leeuwenhoek 1994;66:187-208.

28. Christl SU, Gibson GR, Cummings JH. Role of dietary sulphate in the regulation of methanogenesis in the human large intestine. Gut 1992;33:1234-1238.

29. Christl SU, Murgatroyd PR, Gibson GR, Cummings JH. Production, metabolism and excretion of hydrogen in the large intestine. Gastroenterology 2000;102(4 Pt 1):1269-1277.

30. Cloarec D, Bornet F, Gouilloud S, Barry JL, Salim B, Galmiche JP. Breath hydrogen response to lactulose in healthy subjects: relationship to methane production status. Gut 1990;31:300-304.

31. Levitt MD, Furne JK, Kuskowski M, Ruddy J. Stability of human methanogenic flora over 35 years and a review of insights obtained from breath methane measurements. Clin Gastroenterol Hepatol 2006;4:123-129.

32. Pimentel M, Mayer AG, Park S, Chow EJ, Hasan A, Kong Y. Methane production during lactulose breath test is associated with gastrointestinal disease presentation. Dig Dis Sci 2003;48:86-92.

33. Hwang L, Low K, Khoshini R, et al. Evaluating breath methane as a diagnostic test for constipation-predominant IBS. Dig Dis Sci 2010; 55:398-403.

34. Kim EJ, Paik CN, Chung WC, Lee KM, Yang JM, Choi MG.
The characteristics of the positivity to the lactulose breath test in patients with abdominal bloating. Eur J Gastroenterol Hepatol 2011;23:1144-1149.

35. Weaver GA, Krause JA, Miller TL, Wolin MJ. Incidence of methanogenic bacteria in a sigmoidoscopy population: an association of methanogenic bacteria and diverticulitis. Gut 1986;27:698-704.

36. McKay LF, Eastwood MA, Brydon WG. Methane excretion in man-a study of breath, flatus and faeces. Gut 1985;26:69-74.

37. Hudson MJ, Tomkins AM, Wiggins HS, Drasar BS. Breath methane excretion and intestinal methanogenesis in children and adults in rural Nigeria. Scand J Gastroenterol 1993;28:993-998.

38. O'Keefe SJ, O'Keefe EA, Burke E, Roberts P, Lavender R, Kemp T. Milk-induced malabsorption in malnourished African patients. Am J Clin Nutr 1991;54:130-135

39. Bjorneklett A, Jenssen E. relationship between hydrogen $\left(\mathrm{H}_{2}\right)$ and methane $\left(\mathrm{CH}_{4}\right)$ production in man. Scand J Gastroenterol 1982;17: 985-992.

40. Melcher EA, Levitt MD, Slavin JL. Methane production and bowel function parameters in healthy subjects on low- and high-fiber diets. Nutr Cancer 1991;16:85-92.

41. Montes PG, Saavedra JM, Perman JA. Relationship between methane production and breath hydrogen excretion in lactose-malabsorbing individuals. Dig Dis Sci 1993;38:445-448.

42. Flatz G, Czeizel A, Métneki J, Flatz SD, Kühnau W, Jahn D. Pulmonary hydrogen and methane excretion following ingestion of an unabsorbable carbohydrate: a study of twins. J Pediatr Gastroenterol Nutr 1985;4:936-941.

43. Mello CS, Tahan S, Melli LC, et al. Methane production and small intestinal bacterial overgrowth in children living in a slum. World $\mathrm{J}$ Gastroenterol 2012;18:5932-5939.

44. Heins A, Metz G, Dilawari J, Blendis L, Wiggins H. Breath-methane in patients with cancer of the large bowel. Lancet 1997;2:481-483.

45. Jang SI, Kim JH, Youn YH, Park H, Lee SI, Conklin JL. Relationship between intestinal gas and development of right colon diverticula. J Neurogastroenterol Motil 2010;16:418-423.

46. Kunkel D, Basseri RJ, Makhani MD, Chong K, Chang C, Pimentel $\mathrm{M}$. Methane on breath testing is associated with constipation: a systematic review and meta-analysis. Dig Dis Sci 2011;56:1612-1618.

47. Kim G, Deepinder F, Morales W, et al. Methanobrevibacter smithii is the predominant methanogen in patients with constipation-predominant IBS and methane on breath. Dig Dis Sci 2012;57:3213-3218.

48. Pimentel M, Lin HC, Enayati $\mathrm{P}$, et al. Methane, a gas produced by enteric bacteria, slows intestinal transit and augments small intestinal contractile activity. Am J Physiol Gastrointest Liver Physiol 2006; 290:G1089-G1095.

49. Jahng J, Jung IS, Choi EJ, Concklin JL, Park H. The effects of methane and hydrogen gases produced by enteric bacteria on ileal motility and colonic transit time. Neurogastroenterol Motil 2012;24:185-190, e92.

50. Rao SS, Camilleri M, Hasler WL, et al. Evaluation of gastrointestinal transit in clinical practice: position paper of the American and European Neurogastroenterology and Motility Societies. Neurogastroenterol Motil 2011;23:8-23.

51. Chatterjee S, Park S, Low K, Kong Y, Pimentel M. The degree of breath methane production in IBS correlates with the severity of constipation. Am J Gastroenterol 2007;102:837-841. 
52. Rumessen JJ, Nordgaard-Andersen I, Gudmand-Høyer E. Carbohydrate malabsorption: quantification by methane and hydrogen breath tests. Scand J Gastroenterol 1994;29:826-832.

53. Stephen AM, Wiggins HS, Englyst HN, Cole TJ, Wayman BJ, Cummings JH. The effect of age, sex and level of intake of dietary fiber from wheat on large-bowel function in thirty healthy subjects. $\mathrm{Br}$ J Nutr 1986;56:349-361.

54. El Oufir L, Flourié B, Bruley des Varannes S, et al. Relations between transit time, fermentation products, and hydrogen consuming flora in healthy humans. Gut 1996;38:870-877.

55. Morken MH, Berstad AE, Nysaeter G, Berstad A. Intestinal gas in plain abdominal radiographs does not correlate with symptoms after lactulose challenge. Eur J Gastroenterol Hepatol 2007;19:589-593.

56. Grover M, Kanazawa M, Palsson OS, et al. Small intestinal bacterial overgrowth in irritable bowel syndrome: association with colon motility, bowel symptoms, and psychological distress. Neurogastroenterol Motil 2008;20:998-1008.

57. Attaluri A, Jackson M, Valestin J, Rao SSC. Methanogenic flora is associated with altered colonic transit but not stool characteristics in constipation without IBS. Am J Gastroenterol 2010;105:1407-1411.

58. Lee KM, Paik CN, Chung WC, Yang JM, Choi MG. Breath methane positivity is more common and higher in patients with objectively proven delayed transit constipation. Eur J Gastroenterol Hepatol 2013;25:726-732.

59. Pimentel M, Kong Y, Park S. IBS subjects with methane on lactulose breath test have lower postprandial serotonin levels than subjects with hydrogen. Dig Dis Sci 2004;49:84-87.

60. Rana SV, Sharma S, Sinha SK, Kaur H, Sikander A, Singh K. Incidence of predominant methanogenic flora in irritable bowel syndrome patients and apparently healthy controls from north India. Dig Dis Sci 2009;54:132-135.

61. Bratten JR, Spanier J, Jones MP. Lactulose breath testing does not discriminate patients with irritable bowel syndrome from healthy controls. Am J Gastroenterol 2008;103:958-963.

62. Peled Y, Weinberg D, Hallak A, Gilat T. Factors affecting methane production in humans. Gastrointestinal diseases and alterations of colonic flora. Dig Dis Sci 1987;32:267-271.

63. Majewski M, McCallum RW. Results of small intestinal bacterial overgrowth testing in irritable bowel syndrome patients: clinical profiles and effects of antibiotic trial. Adv Med Sci 2007;52:139-142.

64. Reddymasu SC, Sotarich S, McCallum RW. Small intestinal bacterial overgrowth in irritable bowel syndrome: are there any predictors? BMC Gastroenterology 2010;10:23.

65. Lee KN, Lee OY, Koh DH, et al. Association between symptoms of irritable bowel syndrome and methane and hydrogen on lactulose breath test. J Korean Med Sci 2013;28:901-907.

66. Drossman DA. The functional gastrointestinal disorders and the Rome III process. Gastroenterology 2006;130:1377-1390.

67. Makhani M, Yang J, Mirocha J, Low K, Pimentel M. Factor analysis demonstrates a symptom cluster related to methane and non-methane production in irritable bowel syndrome. J Clin Gastroenterol
2011;45:40-44.

68. Pimentel M, Chow EJ, Lin HC. Normalization of lactulose breath testing correlates with symptoms improvement in irritable bowel syndrome: a double blind, randomized, placebo controlled study. Am J Gastroenterol 2003;98:412-419.

69. Pimentel M, Park S, Mirocha J, Kane SV, Kong Y. The effect of a nonabsorbed oral antibiotic (rifaximin) on the symptoms of the irritable bowel syndrome: a randomized trial. Ann Intern Med 2006; 145:557-563.

70. Sharara AI, Aoun E, Abdul-Baki H, Mounzer R, Sidani S, Elhajj I. A randomized double blind placebo-controlled trial of rifaximin in patients with abdominal bloating and flatulence. Am J Gastroenterol 2006;101:326-333.

71. Pimentel M, Lembo A, Chey WD, et al. Rifaximin therapy for patients with irritable bowel syndrome without constipation. N Engl J Med 2011;364:22-32.

72. Lembo A, Zakko SF, Ferreira NL, et al. Rifaximin for the treatment of diarrhea predominant irritable bowel syndrome: short term treatment leading to long term sustained response. Gastroenterology 2008;134(suppl 1):A545.

73. Pimentel M, Chatterjee S, Chow EJ, Park S, Kong Y. Neomycin improves constipation-predominant irritable bowel syndrome in a fashion that is dependent on the presence of methane gas: subanalysis of a double-blind randomized controlled study. Dig Dis Sci 2006;51:1297-1301.

74. Low K, Hwang L, Hua J, Zhu A, Morales W, Pimentel M. A combination of rifaximin and neomycin is most effective in treating irritable bowel syndrome with methane on lactulose breath test. J Clin Gastroenterol 2010;44:547-550.

75. Shekhar C, Monaghan PJ, Morris J, et al. Rome III Functional constipation and irritable bowel syndrome with constipation are similar disorders within a spectrum of sensitization, regulated by serotonin. Gastroenterology 2013;145:749-757.

76. Furnari M, Savarino E, Buzzone L, et al. Reassessment of the role of methane production between irritable bowel syndrome and functional constipation. J Gastrointestin liver Dis 2012;21:157-163.

77. Ghoshal UC, Srivastava D, Verma A, Misra A. slow transit constipation associated with excess methane production and its improvement following rifaximin therapy. J Neurogastroenterol Motil 2011;17:185-188.

78. Belkind-Gerson J, Kuo B. Gastroparesis: a comprehensive review. Ann Gastroenterol Hepatol 2011;2:1-11.

79. Khayyam U, Sachdeva P, Gomez J, et al. Assessment of symptoms during gastric emptying scintigraphy to correlate symptoms to delayed gastric emptying. Neurogastrointest Motil 2010;22:539-545.

80. Reddymasu SC, McCallum RW. Small intestinal bacterial overgrowth in gastroparesis: are there any predictors? J Clin Gastroenterol 2010;44:e8-e13.

81. George NS, Sankineni A, Parkman HP. Small intestinal overgrowth in gastroparesis. Dig Dis Sci Published Online First: 5 Oct 2012. doi: 10.1007/s10620-012-2426-7 